\title{
Nursing students' perspectives about experiential learning in a research study
}

\author{
Mary T. Rosedale ${ }^{* 1,2}$, Shiela M. Strauss ${ }^{1,2}$, Navjot Kaur ${ }^{1}$, Candice Knight ${ }^{1}$, Dolores Malaspina ${ }^{2}$ \\ ${ }^{1}$ Rory Meyers College of Nursing, New York University, New York, United States \\ ${ }^{2}$ Department of Psychiatry, New York University Langone Medical Center, New York, United States
}

Received: April 22, 2016

DOI: $10.5430 /$ jnep.v6n11p89
Accepted: June 6, 2016

URL: http://dx.doi.org/10.5430/jnep.v6n11p89

\begin{abstract}
Objective: To examine nursing students' perspectives about experiential learning in a research study $(\mathrm{n}=36)$.

Method: Qualitative content analysis was used to analyze student narratives about their 12-week experience participating in an NIH-funded research study.

Results: Findings reveal three essential themes: pleasure and personal rewards of research, improving the lives of patients and new interest in research participation.

Conclusion: Engaging nursing students in research can enhance their interest in lifelong learning, stimulate their willingness to bring new strategies to the clinical interface and can expose them to diverse populations and settings. Importantly, experiential learning in hands-on clinical research improves student nurses' educational experiences and motivates them to advance nursing research.
\end{abstract}

Key Words: Nursing education, Experiential learning, Research, Qualitative content analysis

\section{INTRODUCTION}

An Institute of Medicine ${ }^{[1]}$ report highlights the critical need for more doctoral level nursing education for faculty to implement discipline-specific educational programs and advance nursing science through research. Importantly, nursing is a practice-based profession using an evidence-based approach to healthcare delivery, so advancing knowledge and evaluating practices through research is an important component of nursing education. Certainly, student preparation for nursing research requires them to be educated about the importance of the application of theory and the development of practical skills in real-world situations. In fact, most literature about preparing student nurses for research is focused on teaching strategies that integrate research skill building into didactic instruction, course assignments and group discussion. ${ }^{[2-4]}$ In one study that actually involved a 2-4 week nursing research experience, student nurses completed placements on a clinical research unit and observed the research nurse conduct aspects of the study (i.e., screening and recruitment, obtaining informed consent and the management of studyrelated data). ${ }^{[5]}$ However, nursing students participating in this study did not actively conduct any of the study activities. ${ }^{[5]}$ Without hands-on exposure to research during their clinical education, enabling their professional identities as nurses to encompass applying evidence-based practice and generating new knowledge for practice, ${ }^{[6]}$ many nurses may not view research as a viable career option. Unfortunately, there is a paucity of literature about directly engaging student

\footnotetext{
*Correspondence: Mary T. Rosedale, PhD, PMHNP-BC; Email: mtr3@ nyu.edu; Address: Rory Meyers College of Nursing, New York University, 433 First Avenue, New York, NY, United States.
} 
nurses in clinical research. ${ }^{[7]}$

We therefore report on the participation of nursing students in a research-rich capstone course during their final undergraduate semester at the XXX during the 2013-2014 academic year. The NIH-funded study aimed to examine the use of oral blood to screen for diabetes among dental patients with bleeding gums. The accuracy, acceptability, and feasibility of this novel approach to diabetes screening were compared to the more traditional approach of using finger stick blood testing. The nursing students assisted in research activities, recruiting study participants, obtaining their informed consent, collecting finger stick blood samples, conducting clinical psychological assessments and making 3-month follow-up phone calls to participants with elevated screening results. After their semester-long participation in the study, they submitted papers about their learning experiences. In this article, we examine the students' perspectives and experiences from participating in the hands-on scientific research study. Such an examination sheds light on how students learn via active engagement and how they think about research from the contexts of their personal experiences and as members of the collective endeavor (i.e., member of a team). Importantly, it also informs the development of significant learning opportunities that can promote future interest in conducting research, translating research to clinical settings, and teaching students about research.

\section{Methods}

At the end of their 12-week participation in the NIH-funded study, participating student nurses were asked to submit a 5-10 page paper regarding their involvement in the study. They were specifically asked to describe their experiences in patient recruitment, administering the informed consent for study participation, supporting patients' completion of study-related questionnaires, collecting the blood samples, and sharing blood test results with participating patients who had out-of-range results. The nursing students were encouraged to describe any special challenges that they needed to overcome; anything that was especially gratifying in the process; and how their experiences, level of confidence, and interactions with patients and dental students changed over time. They were also asked to specifically address how their experiences on the research project impacted the way they thought about nursing and nursing research.

Qualitative content analysis was used to systematically analyze the informational content of textual data and uncover themes about the students' research experiences. ${ }^{[8,9]}$ Student papers were read by each of the researchers and coded using an inductive approach, generating salient themes that encompassed and explained as much variation as possible. ${ }^{[10]}$
Using Atlas.ti 6.0 to facilitate data analysis, we developed the initial codes and mapping of themes generated during the analysis and identified and resolved discrepancies in the coding process. ${ }^{[11]}$ Preliminary codes and emerging themes were recorded as they occurred. Ongoing discussions about the observations and insights relevant to understanding the nursing students' experiences of hands-on research occurred. Through constant comparative analysis, recurring themes became evident, and while remaining close to the data, we compared codes, challenged each other's interpretations, and participated in a dialogue to assure a full description of how nursing students experienced their involvement in a research study. Peer debriefing and review of the systematic processes of data collection and data analysis were used to strengthen the rigor of the approach, develop consensus for the final themes and facilitate trustworthiness of findings. The study was approved by the University's Institutional Review Board.

\section{RESUlts}

The content analysis revealed 3 essential themes that described the students' experiential learning when participating in the research. These included: pleasure and personal rewards of research, improving the lives of patients, and new interest in research participation. Themes are elaborated below with direct quotes to exemplify and illuminate their experiences.

\subsection{Pleasure and personal rewards of research}

Each of the students described experiencing pleasure in association with their study involvement. They indicated that they had chosen to become nurses because they wanted to directly interact with patients. They emphasized that the study provided a rewarding learning opportunity to strengthen interpersonal skills and time management and to grow more confident about their transitioning into the role of professional registered nurses. Many students were actually unaware that clinical research involved interaction with patients and colleagues. One student said:

"I perceived research to be mainly academic, but this study has proven that is not the case as there were many opportunities to interact with patients and collaborate with colleagues."

Within the context of the study, students appreciated being able to experiment with different ways of talking with patients, conducting data collection, answering questions and solving problems. Many noted that, in contrast to conventional research classes, active research engagement made them feel inspired and productive. In the words of one student: 
"I was able to engage in a form of creativity and learning not offered through the didactic curriculum."

Another echoed:

"It gave me the opportunity to try new things that are outside the norm of clinical, simulation and lecture."

Students agreed that they had a basic understanding of the components and steps of a research study but

"... it proved to be rewarding to actually participate in one.'

Among the rewards cited were: being part of a team, gaining insight into inter-professional research and practice, working with inspiring people, and bridging the gap between research and evidence-based practice.

Students took pride in knowing that being a research team member meant that they were entrusted with key responsibilities. One student noted:

"Preparing the materials and collecting the blood samples allowed me to have a direct role and responsibility in the study. It was important to be thorough and careful, since incomplete materials or inadequate blood samples could affect the results of the study."

Others described improved data collection techniques, greater assertiveness, and enhanced abilities in multi-tasking, therapeutic communication with patients, communication with an inter-professional team, advocacy for patients, and helping dental providers appreciate the value of nursing.

They also depicted how they had to be resourceful in carrying out study procedures. Generating new ideas and solutions was challenging, gratifying, and could make students feel optimistic about nursing research and clinical practice. It could also help them take responsibility for their own learning and interrelate thoughts about conducting research, oral and systemic health connections, and nursing roles. One student indicated:

"It helped me think outside of the box and engage my mind in the endless possibility of ways to provide nursing care."

Others noted that it was rewarding to interact with patients in a setting (dental clinic) where nurses, and specifically, nurse researchers, were not usually present. A student contrasted his previous experience of basic science research with his work on the clinical research study:

Published by Sciedu Press
"It was very different than working in an academic laboratory. Working in the lab did not provide opportunities for patient interaction and education. The only thing you see about a patient is when samples are shipped to you and labeled with a number. Both areas of research are essential to advance our knowledge and ability to treat human disease, but getting more personal with a patient and directly impacting a life is a powerful idea."

Even when study activities were more administrative, students wrote that they did not lose sight of the "big picture". Participating in a meaningful project was inherently rewarding, and students strove to be flexible in order to meet the needs of the study. Reflecting widely-held views among the group, one student noted:

"There is a lot of administrative work that needs to be finished in order to accomplish the goal of answering the clinical questions. For this study, making folders to take to the dental clinics and physically carrying the blood samples to the lab (for analysis) were two such examples. While these activities have nothing directly to do with the exploration of the clinical questions, they were necessary parts of the research process. I will carry this knowledge forward with me to other projects, with the understanding that research is multifaceted, and the roles one plays within it must remain adaptable."

Enhancing their flexibility, empathy, and perseverance also felt rewarding and meaningful. Several students described the day-to-day challenges of recruitment and sample collection, saying:

"I did not realize how much hard work and dedication went into a study."

and

"I had an idea of how research studies were conducted, but to actually be a part of one gave me a better understanding of what goes into it, the many phases/changes/obstacles that may occur, and the dedication and effort that is needed to complete the goal."

Illustrating her active and personal learning, a student wrote: 
"I had to be more flexible. At my hospital clinicals, the patient usually accepts what I need to do for them that day and understands that doctors and nurses will be in and out. In the study, it was not quite so simple. Patients could be more uncertain, hesitant, or fearful of the unexpected and require more time building trust. They may feel apprehensive by being asked to participate in a research study. To make the patient feel at ease, rapport needs to be built."

\subsection{Improving the lives of patients}

The greatest motivation for research involvement was to improve patients' lives. Even when students were intimidated about research or insecure about their nursing skills, the desire to help patients prompted them to overcome barriers. One student said:

"It made me step outside my comfort zone in a good way, and made me realize I am willing to do whatever promotes betterment of the patient and the possibility of a patient's positive outcome. It made me realize how much work is required to make changes, but it is worth the effort."

Students were very eager for interaction with patients. When they realized that educating patients about the relationship between periodontal disease and diabetes could lead to patients' screening for diabetes and the potential for subsequent improved health behaviors, the students embraced research. This was further reinforced when patients (usually at the follow-up call) expressed considerable appreciation for the study and for their contact with the students. With clear delight, students wrote:

"So many patients were grateful for taking part in this study!"

Reflecting the views of all, a student emphasized:

"If you can learn how to prevent worsening human health, it is all worth the time and effort. The huge difference (between participating in a study and taking a research class) is that I am actually taking part in the intervention phase. I am providing action to a growing, global health issue."

As they became immersed in the study, students began to view their study responsibilities more broadly. They were not just collecting a blood sample, but were potentially providing the patient with key health information about the results of testing that sample. They were "supporting change to improve patient outcomes". Notably, many began to observe a "ripple-effect". The health education provided to one patient could affect situations not directly related to the initial education interaction. They observed patients sharing information about periodontal disease and diabetes with others and encouraging others to be screened in our study at dental clinics. Students witnessed how dissemination of information about the study broadened its impact. Exemplifying this, one student wrote:

"Every time I take a blood sample, I can be altering someone's life. Each time I educate someone on diabetes, they take a little bit of knowledge home. Maybe they convey it to someone else, and because of a small, two hour interaction, someone else's life could also be changed."

Participation in the study also prompted a shift in thinking. Students who had been focused on health from the perspective of treatment and cure began to also consider prevention, early detection, education, and follow-up. This led to reflection about the role of a professional nurse.

"I once thought of nursing as a profession that treats or cures patients, but now I know that it encompasses other factors, such as prevention, education, and follow-up. I have learned that as a nurse, I am not simply there to fix or treat an ailment. I must also implement disease prevention methods, provide teaching and health promotion to patients, and follow-up with patients."

Students reported that they planned to incorporate oral health and diabetes screenings into future health assessments. They had "high hopes" that diabetes screenings in dental clinics would become standard practice, and saw the need for a variety of health screenings in new venues. By participating in the study, they realized that there were great opportunities for nurses to improve the lives of patients. Illustrating this point, a student wrote:

"I did not think nursing could open so many opportunities outside the hospital setting. The diabetes screening project for dental patients showed me patients need to be screened in as many places as possible as they may not be aware they have certain conditions. The results from the screening were shocking to me as many 
of the patients were in the range of pre-diabetic or in the diabetic range. It's rewarding knowing that we were doing a good thing by screening patients and following up with their results, making sure they understood what the results mean and what actions they should take."

Students wrote that improving the lives of patients also meant increasingly and more broadly embracing the role of patient advocate and teaching patients and other clinical professionals about nursing. This included teaching others how nursing research can affect daily clinical practice and the lives of patients, supporting health policy to assure insurance coverage for disease prevention, screening, and health care followup. They emphasized that nurses' knowledge and skills in patient education allow them to effectively translate information about oral and systemic health problems in empathic and sensitive language that patients can understand and use. Summing it up, one student stated:

"It made me think that by effectively translating research into practice, I can genuinely advocate for patients and a better healthcare system."

\subsection{New interest in research participation}

Prior to study participation, students said that they never pictured themselves being involved with research and were even "terrified" of research. One student noted:

"It seemed like such a foreign concept and something I would never fully be able to grasp in terms of higher level mathematics and statistics.”

Among the misconceptions about research, were the following: there was no patient interaction; it was boring; and it had little connection to clinical care. During the course of the study, students reported that their perspectives about research changed.

With very few exceptions, the students' previous exposure to research was limited to a didactic research class. Seeing themselves as future clinicians, some did not fully appreciate the reasons for taking a research class, systematically studying a clinical problem, learning how research informed clinical practice, or how research was used to improve patient outcomes. As depicted in the quote below, the semester-long participation in a research study provided sufficient time for an interest in research to "grow".

"I never thought I would be interested in research, but this study was presented in such a relevant way, my interest continued to grow each week. This diabetes screening study was unique training for interacting with all types of patients and engaging in teamwork among peers. I always looked forward to my time at the dental clinic, working with patients, as well as my time making follow-up phone calls."

Further supporting that research interest grows with exposure over time, another student described getting a

“...taste for research."

Indicating her future interest in a research career, she said:

"This has given me a taste for the complexity of research, how clinical questions are formed, and how research is executed to answer these questions."

Another student emphasized that the continuity of participation over the course of the semester made her look forward to her research day:

"It was my favorite day in the week."

Students said that participating in a hands-on research study was "an eye-opener" because involvement helped them make connections between clinical presentations of illness and how research informs early screening, health promotion, and treatment. Because students had the vantage point of interacting with patients from recruitment through follow-up 3 months later, they interacted with patients who were unaware of elevated glucose, received positive screening results, contacted primary care providers or received referrals. They talked with patients about lifestyle and medication changes, as well as barriers to change. They had not considered how they could actively advance science through research, but were now interested in considering a research career. Exemplifying this, a student wrote:

"I am now able to connect things I see in the hospital setting to research and see the important role that research plays in nursing. Instead of just being passive about many issues I encounter in the hospital, I am now interested in doing research and learning more about how I can make a difference in those issues."

Another student said:

"This research project has opened up an entirely new side of research to me. I was surprised 
to discover that I loved the data collection, patient interaction, and informed consent part of the study."

Reflecting multiple student experiences, one student wrote:

"I realized that research is another role that nurses can take. Being a nurse researcher means you will still be playing an active role at the front line of protecting and educating patients. Nursing research creates improvement in patient safety, satisfaction, and well-being."

Students described research as a way to "keep growing and learning" and to make a valuable contribution to the nursing profession. By playing an active role in the overall progress of the study, students "could see the difference they were making". Summing it up, one student expressed:

"It is important that nurses contribute to research as they will be the ones utilizing this information. As a field, we (nurses) are more in touch with the patient and the community. Our knowledge on this is important when assessing a problem, planning a study, and implementing the process, especially when the subjects are people. This study has fostered my understanding of this process and my interest and future participation in research."

\section{Discussion}

Results indicate that nursing students who participated in a hands-on research study discovered the pleasure and personal rewards of research, were most motivated by improving the lives of patients, and began to think of research as a potential career option. We found that when nursing students were immersed in an NIH-funded study, with defined responsibilities, and consistent participation over a 12-week semester was expected, it enabled them to rethink their views about research and anticipate the possibility of a nursing research career. This is important because transforming the US health care system to meet the demand for safe, quality, and affordable care requires that nurses practice to the full extent of their education and training and advance the science of nursing. ${ }^{[1]}$ Consistent with Benner and colleagues, ${ }^{[12]}$ we found that the professional identity of student nurses began to include an interest in research when active research activity helped them develop new habits of thoughts and action, interact in the inter-professional dimension and become part of a team, and understand that, as with all of nursing, research entailed the development of skills and understanding of patient care over time.
Research about nursing students' experiences in the clinical learning environment supports that learning is facilitated when the environment is conducive to learning, students feel like members of a team, and there are qualified nurses willing to teach. ${ }^{[13]}$ While students in our study did describe the environment as "learning-friendly", appreciated being part of a team, and had ongoing access to nursing faculty, there were no practicing nurses in the dental clinics. Because most clinical learning rotations take place in healthcare environments rich with practicing nurses (i.e., hospital or community health center), and the dental clinics were "one of the only places you do not typically see nurses", nursing students assumed the responsibility of educating patients and dental providers about nursing. Without prompting, they began teaching dental students and dental hygienists about the holistic nature of nursing practice, learning about these allied disciplines, discussing how interdisciplinary collaboration in practice and research reflected the values of nursing and how effectively nurses could integrate into dental clinic settings. Most importantly for students, they were able to interact with and care for actual patients in a variety of ways (i.e., teaching patients about the oral-systemic health connection, obtaining finger stick blood samples, sensitively explaining the meaning of elevated readings and the importance of clinical follow-up). Because they were participating in a research study rather than a traditional clinical learning environment, they were providing health screening, teaching and advocacy in ways that would otherwise not have been available to patients in the dental clinic. Consistent with previous research, students were gratified when they were given professional nursing responsibilities with opportunities for "hands on" care. ${ }^{[13]}$

Supporting the findings of our study, organizations such as the Council on Undergraduate Research ${ }^{[14]}$ advocate for the inclusion of research experiences that foster student involvement across baccalaureate curricula. The National Institute for Nursing Research ${ }^{[15]}$ supports the education of nursing doctoral students who are motivated to pursue research careers. Our study suggests that when student nurses are actively engaged in research, interest in research can be cultivated as student nurses form their professional identities. There are multiple models for including students in planned curricular research projects with faculty. ${ }^{[16-19]}$ Our students tell us that when they are entrusted to conduct many aspects of a research study, and expected to do so each week for 12 weeks, it changes their views, commitment, and professional identification with the value of nursing research and professional practice.

The clinical learning environment is a vital component of nursing education and provides unique learning opportunities where students interact with patients and allied clinical 
professionals in "real-world" situations. The culture of the healthcare workplace critically establishes the value of learning for the students. ${ }^{[13]}$ However, in the typical clinical practicum, nursing students "shadow" expert nurses, may be assigned the tasks of nursing assistants, ${ }^{[13]}$ and have little connection to research or how research affects evidencebased practice. Nursing students are understandably eager to actively cultivate skills such as blood collection, and practice important aspects of nursing practice such as health teaching, promotion, advocacy, and interdisciplinary collaboration. Active participation in a research study can facilitate the shift from student-apprentice to student-professional because the students are taught, supported, and expected to assume a set of professional nursing responsibilities (i.e., from obtaining blood samples to therapeutically communicating sensitive health information).

Participating in hands-on clinical research improves student nurses' educational experiences of research and motivates them to advance nursing research and to understand and employ evidence-based research in their practice. Although the students' research involvement was facilitated by an NIHfunded research study that encouraged the participation of student nurses, there are often many opportunities for undergraduate and graduate students to be involved in research. This is especially the case when conducting preliminary studies in anticipation of a grant application. The recruitment and informed consent process in which students can be involved especially enables students to interact with patients while answering their questions about the study. During this process, they can also learn about professional socialization, time management, and provide prevention education about an illness related to the area of research. When questionnaires are part of the research, students can assist research participants with limited language or health literacy, thereby improving

\section{REFERENCES}

[1] Institute of Medicine. The future of nursing: leading change, advancing health. Press NA, ed. Washington, DC. 2010.

[2] Kessler TA, Alverson EM. Mentoring undergraduate nursing students in research. Nursing Education Perspectives. 2014; 35(4): 262-264. http://dx.doi.org/10.5480/11-555.1

[3] Oberne AB. Practice makes perfect: Integrating research skill building into undergraduate courses. Pedagogy in Health Promotion. 2015; 1(3): 117-122. http://dx.doi.org/10.1177/2373379915583 677

[4] Tsai HM, Cheng CY, Chang CH, et al. Preparing the future nurses for nursing research: A creative teaching strategy for RN-BSN students. International Journal of Nursing Practice. 2014; 20(1): 25-31. PMid:24580972. http://dx.doi.org/10.1111/ijn.12119

Published by Sciedu Press the student's communication skills, facilitating effective exchange of health information, empowering patients to ask questions and make decisions, and ensuring more accurate participant responses. Active involvement in research also encourages students embarking on a professional career to take a "longer view" and consider trajectories for faculty and research positions earlier in their careers.

We acknowledge as limitations of our findings the fact that the student sample was a purposive one, and that the student papers from which our findings are drawn may have presented a socially desirable account of their thoughts and experiences. Because the student papers were a component of their final grade, their comments may have been uniformly more positive than they might have been had another data source been used.

\section{Conclusion}

Nursing students who were immersed in an NIH-funded research study, with defined responsibilities and expected consistent participation over a 12-week semester, could rethink their views about research and anticipate the possibility of a research career. Promoting a career interest in research is vital to advancing nursing science because research builds the scientific foundation for evidence-based, nursing clinical practice. It is the role of nurse educators to promote the professional practice and discipline of nursing as well as to prepare future nurse clinicians, educators and researchers.

\section{ACKNOWLEDGEMENTS}

The research received financial support from National Institute of Dental and Craniofacial Research (grant 1R15DE023201).

\section{CONFlicts OF InTEREST Disclosure}

The authors declare that they have no conflicts of interest.
[5] Naylor GA, Hanson A, Evely J, et al. Nursing student placements in clinical research. Nursing Standard. 2014; 29(2): 3743. PMid:25204950. http://dx.doi .org/10.7748/ns.29.2.3 7.e8683

[6] National Institute for Nursing Research. 2015. Available from: http://www.ninr.nih.gov/

[7] Gelling L. Research is part of real life. Nurse Researcher. 2012; 19(4): 3. http://dx.doi.org/10.7748/nr.19.4.3.s2

[8] Forman J, Damschroder L. Qualitative content analysis: Empirical Research for Bioethics: A Primer. Oxford, UK: Elsevier Publishing. 2008.

[9] Mayring P. Qualitative Content Analysis. Forum: Qualitative Social Research. 2000; 1(2): Art.20. Available from: http://nbn-resol ving.de/urn:nbn:de:0114-fqs0002204 
[10] Thorne S. Data analysis in qualitative research. Evidence Based Nursing. 2000; 3(3): 68-70. http://dx.doi.org/10.1136/ebn.3.3 .68

[11] ATLAS.ti Scientific Software GmbH (Version 6.0) [Computer program]. Berlin, Germany: Springer. 2011.

[12] Benner P, Sutphen M, Leonard V, et al. Educating nurses: A call for radical transformation. San Francisco, CA: Jossey-Bass. 2010.

[13] Hooven K. Nursing students' qualitative experiences in the medicalsurgical clinical learning environment: A cross cultural integrative review. Journal of Nursing Education. 2015; 54(8): 421-429. PMid:26230161. http://dx.doi.org/10.3928/01484834-201 50717-01

[14] Council on Undergraduate Research. 2015. Available from: http: //www. cur.org/aboutcur/

[15] National League for Nursing. NLN Education Competencies Model. 2015. Available from: http://www.nln.org/docs/default-s ource/about/nln-vision-series-\%28position-stateme nts $\% 29 /$ nlnvision_1.pdf?sfvrsn=4

[16] Madleco BL, Schwartz R. Faculty/student collaboration: an approach to teaching nursing research. Nurse Educator. 2002; 27(2): 61-64. http://dx.doi.org/10.1097/00006223-200203000-00005

[17] Ravert P, Boyer B, Harmon K, et al. Learning nursing research through faculty-mentored projects. Nurse Educator. 2004; 29(4): 170-174. http://dx.doi.org/10.1097/00006223-200407000 $-00014$

[18] Wheeler EC, Hardie T, Schell K, et al. Symbiosis - undergraduate research mentoring and faculty scholarship in nursing. Nursing Outlook. 2008; 56(1): 9-15. PMid:18237619. http://dx.doi.org/1 $0.1016 /$ j.outlook.2007.09.001

[19] Reutter L, Paul P, Visram A, et al. Incorporating a research apprenticeship model in a Canadian nursing Honors Program. Nurse Education Today. 2010; 30(6): 562-567. PMid:20031283. http: //dx.doi.org/10.1016/j.nedt.2009.12.001 